\title{
Mediating Effects of Mental Health Problems in a Clinical Sample of Adolescents with Obesity
}

\author{
Petra Hampel $^{a}$ Rainer Stachow ${ }^{b} \quad$ Julian Wienert ${ }^{c, d, e}$ \\ anstitute of Health, Nutrition, and Sport Sciences, Europa-Universität Flensburg, Flensburg, Germany; ${ }^{\mathrm{b} O s t s e e k l i n i k}$ \\ Grömitz, REHASAN Klinik Grömitz Betriebs GmbH, Grömitz, Germany; ' Leibniz Institute for Prevention Research \\ and Epidemiology - BIPS, University of Bremen, Bremen, Germany; dLeibniz ScienceCampus Digital Public Health \\ Bremen, Bremen, Germany; 'IU International University of Applied Sciences, Bad Reichenhall, Germany
}

\section{Keywords}

Obesity · Parent proxy-reported mental health problems .

Health-related quality of life · Adolescents · Mediation analysis

\begin{abstract}
Introduction: The prevalence rates of obesity have increased in recent decades; despite leveling off in recent German studies among children and adolescents, obesity rates remain high. Psychosocial factors have an adverse impact on the maintenance of obesity. Hence, this study examined the mediating effects of mental health problems on the relation between the body mass index standard deviation score (BMI-SDS) and global health-related quality of life (HRQoL) among adolescent inpatients with obesity while controlling for gender and age-group. Methods: Three simple mediation analyses with gender and age-group as covariates were conducted for $n=313$ adolescents with obesity $\left(n_{\text {female }}=\right.$ $193,61.7 \%)$ aged 12-17 ( $M=14.19, \mathrm{SD}=1.52$; BMI-SDS: $\mathrm{M}=$ $2.67, \mathrm{SD}=0.52)$. The adolescents were asked to report their global HRQoL at admission, and their parents estimated the children's mental health problems at home prior to inpatient rehabilitation. Results: Emotional, peer-related, and con-
\end{abstract}

karger@karger.com www.karger.com/ofa

Karger $\stackrel{\text { ' }}{5}$

GOPEN ACCESS
(C) 2021 The Author(s)

Published by S. Karger AG, Basel

This is an Open Access article licensed under the Creative Commons Attribution-NonCommercial-4.0 International License (CC BY-NC) (http://www.karger.com/Services/OpenAccessLicense), applicable to the online version of the article only. Usage and distribution for commercial purposes requires written permission. duct problems mediated the unfavorable effects of BMI-SDS on global HRQoL, showing high, moderate, and small effect sizes, respectively (completely standardized indirect effect of emotional problems: $\beta=-0.09, \mathrm{SE}=0.03,95 \% \mathrm{~B}-\mathrm{Cl}=-0.15$ to -0.04 ; conduct problems: $\beta=-0.03, \mathrm{SE}=0.02,95 \% \mathrm{~B}-\mathrm{Cl}=$ -0.06 to -0.01 ; peer-related problems: $\beta=-0.10, \mathrm{SE}=0.03$, $95 \% \mathrm{~B}-\mathrm{Cl}=-0.16$ to -0.05$)$. Conclusion: Mental health problems may be one salient pathway through which BMI-SDS impairs global HRQoL among adolescents with obesity. Hence, inpatient rehabilitation programs for adolescents with obesity should increase their focus more on the development of psychosocial skills. Thus, the promotion of emotion regulation and social-emotional competencies is suggested.

(c) 2021 The Author(s).

Published by S. Karger AG, Basel

\section{Introduction}

The prevalence rates of obesity over the life span have increased significantly in recent decades; in the US population, rates increased from 1999 to 2016, mainly among adolescents [1]. Similarly, substantial increases in overweight and obesity were found from 1980 to 2013, espe- 
cially among children and adolescents in developed countries [2]. Increases were also observed in a large-scale cohort sequence study in Germany (KiGGS); a 3-fold increase in obesity was found from 1985-1999 to 20032006 [3], but the prevalence rates leveled off and remained high in 2009-2012 [4, 5]. Data from 2014 to 2017 showed prevalence rates of $9.5 \%$ for overweight and $5.9 \%$ for obesity [6].

Unfavorable psychosocial factors have been proven to be very important risk factors for the development and maintenance of obesity $[7,8]$. Impaired health-related quality of life (HRQoL) has been associated among children and adolescents with obesity [9]. This association might have a negative impact on school achievement and treatment adherence in children with obesity [10]. A recent literature review comparing children and adolescents with overweight or obesity to healthy controls reported findings of a lower HRQoL in 31 of the 34 selected articles [9]. These findings were confirmed by further studies $[9,11,12]$. Regarding gender effects on HRQoL, females with overweight or obesity reported lower HRQoL than males $[9,13,14]$. In contrast, inconclusive results were found for age effects. Regarding the type of chronic condition, some research has suggested that impaired HRQoL among children and adolescents with overweight or obesity is even more pronounced, especially in the emotional dimension $[15,16]$.

Moreover, research has shown close positive relations between obesity and mental health problems [17]; in a prospective study with a 2-year follow-up assessment, adolescent obesity was significantly associated with increased self-reported mental health problems [18]. Similarly, in a cross-sectional population-based study, obesity was linked with a 2.5 -fold increase in the risk of psychological problems [19]. To further summarize the results, more evidence has been provided for increased internalizing problems (i.e., depression and anxiety) than for externalizing problems (i.e., aggressive behavior); childhood overweight or obesity was associated with a 4 -fold increase in the risk of developing late-life depression in a population-based study [20].

Addressing the relevance of gender in the context of mental health problems, past research has provided mixed results for children and adolescents with obesity. Significant relations between obesity or increased body mass index (BMI) and higher internalizing problems have been ascertained predominately for females in crosssectional $[21,22]$ and prospective population-based studies $([23,24]$; for a review, see also [25]). An increased risk of emotional problems has been reported for females only
[19]. In contrast, another study among early and late adolescents ascertained a positive association with depressive mood among males, but not among females [26]. In addition, females with obesity were more likely than males to have externalizing disorders [22]. The results of age effects underscore that early adolescents with obesity seem to be very vulnerable to the development of anxiety disorders [22] and impaired global mental health [19].

Research on the association between mental health problems and HRQoL has supported an unfavorable impact of mental health problems; in a population-based study, higher levels of self-reported mental health problems were the most significant risk factor for impaired global HRQoL [27]. In sum, prior research has neglected to examine this association among children and adolescents with obesity.

Previous research on potential psychological mediators has focused on the mediating effects of weight-related teasing, body dissatisfaction, or victimization. Overall, these psychological factors mediated the inverse association of BMI or obesity and global HRQoL [28], psychological well-being [29], and emotional well-being [26]. Similarly, in the only longitudinal study among adolescents, the positive association between obesity and mental health problems 2 years later was reduced but still remained significant when victimization was included as a mediating factor [18].

Some direct effects of BMI or obesity on impaired psychosocial health can be conclusively reported, with a more pronounced association among clinical samples, females, and adolescents. Nevertheless, research on potential mechanisms is scarce, and the results are contradictory. Thus, more research on mediating psychological mechanisms is needed to illuminate the potential underlying interrelations. Given the moderating effects of age and gender, consideration of these organismic variables is also recommended. Finally, the study of this relation during a vulnerable phase of development, adolescence, is particularly interesting. The developmental period of adolescence is linked to significant increases in perceived stress, maladaptive coping, and psychological maladjustment [30]. The present study aimed to close these gaps in the research by clarifying the interrelation among BMI, mental health problems, and global HRQoL in adolescent inpatients with obesity. It was hypothesized that the adverse impact of a higher BMI on global HRQoL would be mediated by mental health problems. Important implications for the modification of existing multimodal intervention programs can be drawn from the results. 


\section{Materials and Methods}

\section{Participants and Procedure}

In total, $N=313$ adolescents with obesity $\left(n_{\text {female }}=193,61.7 \%\right)$ aged $12-17(\mathrm{M}=14.19, \mathrm{SD}=1.52$ years $)$ were included in the convenience sample, that was recruited from an inpatient rehabilitation program. Rehabilitation is a medical program, which is intended to enable individuals with chronic impairments or diseases to (i) cope with their impairment or disease and its consequences and (ii) participate in normal life in society independently and largely independently. It contains integrated intervention modules with medical, psychological, and educational treatment elements. The participants attended 5th to 12th grade; however, the majority of them were seventh and ninth graders from junior high schools (64.2\%). They had not previously participated in outpatient treatment, but it was recommended that they seek outpatient treatment after rehabilitation. The adolescents included in this study needed to have good reading and writing skills. The main diagnosis had to be obesity (BMI $>97$ th percentile). The mean BMI standard deviation score (BMI-SDS) was 2.67 (SD = 0.52; range: $1.17-4.40$ ). None of the participants were diagnosed with psychiatric disorders. A minority of the parents and children declined participation in the study (5\%).

This study used cross-sectional data collected from 2 research projects in inpatient rehabilitation. The adolescents completed self-reports upon admission to the inpatient rehabilitation program of a specialized rehabilitation clinic for children and adolescents of the German Pension Insurance (DRV) North in Westerland/Sylt (Germany) between 2013 and 2017. The duration of the rehabilitation program varied between 4 (50.8\%) and 6 weeks (49.2\%). After pre-assessment, all of the adolescents were treated with an integrated program, that adhered to current guidelines [31] and consisted of physical exercises, nutritional training, and psychosocial intervention. The parents evaluated their children's mental health problems at home immediately before their children entered the inpatient rehabilitation program.

\section{Measures}

Body Mass Index Standard Deviation Score

Weight and height were assessed with the participants wearing light clothing and no shoes. Measurements were performed by physicians during the medical admission examination and converted into the BMS-SDS in accordance with gender- and age-specific reference scores [32].

Mental Health Problems

The parents assessed their children's mental health problems using the German version of the Strengths and Difficulties Questionnaire (SDQ-Deu parent proxy 4-17 [33]). The 25 items of the questionnaire were rated from "not true" (0) to "certainly true" (2). Five subtests were used in the present study: emotional problems, conduct problems, hyperactivity, peer-related problems, and prosocial behavior. Subtest scores could vary between 0 and 10. The internal consistency of the SDQ-Deu parent proxy was good in previous studies $[34,35]$. Scale analyses revealed Cronbach alphas from 0.63 to 0.72 (emotional problems: 0.72 , conduct problems: 0.61 , hyperactivity: 0.72 , peer-related problems: 0.63 , and prosocial behavior: 0.63 ). Clinical scores (cutoff values) were determined according to Woerner et al. [36] and categorized as "subclinical," "borderline," and "clinical." Due to concerns re- garding lower reliability scores for the self-report form of the SDQ [18], the parent proxy reports were considered in the present analyses.

Health-Related Quality of Life

Using the German version of the disabled children's quality of life measure (DISABKIDS Chronic Generic Measure; DCGM-37; [37]), HRQoL was assessed by self-report. The 5 dimensions "independence," "limitation," "emotion," "inclusion," and "exclusion" were evaluated in relation to the previous week. The dimension "medications/treatment" was not included in the study because it was irrelevant to the research question. The total score for the remaining 31 items was calculated and was used in this study. The item raw scores were transformed into percentage scores ranging from 0 to 100 . High values indicate a high HRQoL. The good psychometric quality of the DCGM-37 has been proven in various studies $[38,39]$.

\section{Statistical Analyses}

All statistical analyses were performed using IBM SPSS Statistics 26. Mean differences in gender and age-group were determined using independent Student's $t$ tests, and inequality in variance was corrected by applying the Welch test. Mediation analyses were performed using the SPSS PROCESS version 3.4 macro, which uses regression analysis to test for mediation effects [40]. Simple mediation models with the 2 covariates "gender" and "agegroup" were performed (gender: female $=1$, male $=2$; age-group: $12-14$ years, i.e., early adolescents $=1,15-17$ years, i.e., late adolescents $=2$ ). The empirically proven gender and age effects were controlled for by considering the covariates. A significance level of $5 \%$ for 2 -sided tests was set.

The assumptions of the mediation analyses were tested by partial correlations between the model variables; additionally, the control variables were taken into account given that significant correlations of all model variables are a prerequisite for mediation analyses [41]. Again, a significance level of 5\% for two-sided tests was applied. Linearity and homoscedasticity were given as prerequisites for the multiple linear regression analysis. Since PROCESS centers the variables, multicollinearity is reduced; thus, the results can be interpreted more accurately [42]. However, the condition indices varied from 26 to 27 and did not exceed the critical value of 30 [43]. In contrast, a normal distribution of residuals was not always given. However, this violation can be overcome by using bootstrap confidence intervals and a sufficiently large sample [40, 41].

The results of the mediation analyses were interpreted using the corrected $R^{2}$ based on the number of predictors in the regression model. According to Cohen [44], the effect size $R^{2}$ can be interpreted as small (0.02), medium (0.13), or large (0.26). Statistical validation of the indirect effect was performed using bootstrap confidence intervals (number of bootstrap samples: 5,000 ). The bootstrap confidence intervals of the unstandardized, partially standardized, and completely standardized effect sizes were considered [40,41]; a significant mediation effect was reported if the interval between the lower limit and the upper limit of the $95 \%$ bootstrap confidence interval of all 3 effects did not contain zero. Consistent with Hayes [40], no distinction was made between partial and complete mediation in the present presentation of results. 
Table 1. Frequencies $(\Sigma)$ and percentages (\%) of adolescents for mental health problems by manifestation, stratified by gender and agegroup $(N=313)$

\begin{tabular}{|c|c|c|c|c|c|c|c|c|c|c|c|c|c|c|c|c|}
\hline \multirow[t]{2}{*}{ Variable } & & \multicolumn{3}{|c|}{$\begin{array}{l}\text { Scores } \\
\text { (total sample) }\end{array}$} & \multicolumn{3}{|c|}{$\begin{array}{l}\text { Scores } \\
(n=193 \text { females })\end{array}$} & \multicolumn{3}{|c|}{$\begin{array}{l}\text { Scores } \\
(n=120 \text { males })\end{array}$} & \multicolumn{3}{|c|}{$\begin{array}{l}\text { Scores } \\
(n=181 \text { 12-14-year-olds })\end{array}$} & \multicolumn{3}{|c|}{$\begin{array}{l}\text { Scores } \\
(n=132 \text { 15-17-year-olds) }\end{array}$} \\
\hline & & $\mathrm{sc}$ & $b$ & $c$ & $\mathrm{sc}$ & $b$ & $c$ & sc & $b$ & $c$ & sc & $b$ & $c$ & sc & $b$ & $c$ \\
\hline \multirow{6}{*}{$\begin{array}{l}\text { Emotional } \\
\text { problems } \\
\text { Conduct } \\
\text { problems } \\
\text { Hyperactivity }\end{array}$} & $\Sigma$ & 226 & 25 & 62 & 142 & 19 & 32 & 84 & 6 & 30 & 132 & 13 & 36 & 94 & 12 & 26 \\
\hline & $\%$ & 72.2 & 8.0 & 19.8 & 73.6 & 9.8 & 16.6 & 70.0 & 5.0 & 25.0 & 72.9 & 7.2 & 19.9 & 71.2 & 9.1 & 19.7 \\
\hline & $\Sigma$ & 231 & 38 & 44 & 145 & 24 & 24 & 86 & 14 & 20 & 128 & 24 & 29 & 103 & 14 & 15 \\
\hline & $\%$ & 73.8 & 12.1 & 12.1 & 75.1 & 12.4 & 12.4 & 71.7 & 11.7 & 16.7 & 70.7 & 13.3 & 16.0 & 78.0 & 10.6 & 11.4 \\
\hline & $\Sigma$ & 267 & 24 & 22 & 172 & 13 & 8 & 95 & 11 & 14 & 147 & 15 & 19 & 120 & 9 & 3 \\
\hline & $\%$ & 85.3 & 7.7 & 7.0 & 89.1 & 6.7 & 4.1 & 79.2 & 9.2 & 11.7 & 81.2 & 8.3 & 10.5 & 90.9 & 6.8 & 2.3 \\
\hline \multirow{4}{*}{$\begin{array}{l}\text { Peer-related } \\
\text { problems } \\
\text { Prosocial } \\
\text { behavior }\end{array}$} & $\Sigma$ & 213 & 59 & 41 & 136 & 32 & 25 & 77 & 27 & 16 & 121 & 40 & 20 & 92 & 19 & 21 \\
\hline & $\%$ & 68.1 & 18.8 & 13.1 & 70.5 & 16.6 & 13.0 & 64.2 & 22.5 & 13.3 & 66.9 & 22.1 & 11.0 & 69.7 & 14.4 & 15.9 \\
\hline & $\sum$ & 289 & 13 & 11 & 183 & 7 & 3 & 106 & 6 & 8 & 163 & 10 & 8 & 126 & 3 & 3 \\
\hline & $\%$ & 92.3 & 4.2 & 3.5 & 94.8 & 3.6 & 1.6 & 88.3 & 5.0 & 6.7 & 90.1 & 5.5 & 4.4 & 95.5 & 2.3 & 2.3 \\
\hline
\end{tabular}

sc, subclinical; $b$, borderline; $c$, clinical.

Table 2. M, SDs, and Min-Max for the potential mediation variables stratified by gender and age-group

\begin{tabular}{|c|c|c|c|c|c|c|c|c|c|c|c|c|}
\hline \multirow[t]{2}{*}{ Variable } & \multicolumn{4}{|c|}{ Total $(N=313)$} & \multicolumn{4}{|c|}{ Gender } & \multicolumn{4}{|c|}{ Age-group } \\
\hline & M & $\mathrm{SD}$ & $\min$ & $\max$ & M & $\mathrm{SD}$ & M & $\mathrm{SD}$ & M & SD & M & SD \\
\hline BMI-SDS & 2.67 & 0.52 & 1.17 & 4.40 & 2.72 & 0.57 & $2.58^{\mathrm{a}}$ & 0.41 & 2.53 & 0.41 & $2.86^{\mathrm{c}}$ & 0.58 \\
\hline Emotional problems & 4.00 & 2.52 & 0.00 & 10.00 & 4.02 & 2.39 & 3.98 & 2.73 & 3.88 & 2.50 & 4.17 & 2.55 \\
\hline Conduct problems & 2.46 & 1.80 & 0.00 & 7.00 & 2.37 & 1.77 & 2.59 & 1.84 & 2.59 & 1.86 & 2.27 & 1.70 \\
\hline Prosocial behavior & 8.11 & 1.71 & 0.00 & 10.00 & 8.30 & 1.64 & 7.79 & 1.77 & 8.04 & 1.82 & 8.20 & 1.54 \\
\hline HRQoL & 62.69 & 16.61 & 11.29 & 100.00 & 62.26 & 16.86 & 63.39 & 16.24 & 62.94 & 16.07 & 62.35 & 17.36 \\
\hline
\end{tabular}

M, means; SDs, standard deviations; Min-Max, ranges; BMI-SDS, body mass index standard deviation score; HRQoL, health-related quality of life. ${ }^{\mathrm{a}}$ Female $>$ male, $p=0.011 .{ }^{\mathrm{b}}$ Female $<$ male, $p<0.001 .{ }^{\mathrm{c}} 12-14$ years $<15-17$ years, $p<0.001 .{ }^{\mathrm{d}} 12-14$ years $>15-17$ years, $p=0.001$.

\section{Results}

\section{Descriptive Statistics}

The distributions of clinical scores for mental health problems among the total sample of $N=313$ adolescents are presented in Table 1 . In contrast to the expected distribution of $80 \%$ normative scores and $10 \%$ each for borderline and clinical scores, the parents reported high clinical scores for emotional problems. Regarding gender, the male patients showed higher clinical scores for emotional problems and for hyperactivity. In terms of age-group, younger patients had higher percentages of clinical scores for conduct problems and hyperactivity than older patients did.
The ranges for the total sample indicate that the responses to HRQoL subscales were well distributed, suggesting that participants used the entire scale for their responses (Table 2). This was also true for the psychological problem subscales, with the exception of the conduct problems subscale, for which the parents used only the lower two-thirds of the response scale.

\section{Differences in Gender and Age-Group}

In independent Student's $t$ tests, gender effects were only ascertained for the BMI-SDS and hyperactivity; females showed a significantly higher BMI-SDS ( $t$ [303.2] $=2.57, p=0.011)$ and lower levels of hyperactivity than males $(t[313]=-4.15, p<0.001$; Table 2$)$. Moreover, age 
Table 3. Partial correlations of the potential mediation variables controlled for "gender" and "age-group" $(N=$ 313)

\begin{tabular}{lccccccc}
\hline Variable & BMI & Emo & Beh & Hyp & Per & Soc & HRQoL \\
\hline BMI-SDS (BMI) & 1.00 & & & & & & \\
Emotional problems (Emo) & $0.19^{* *}$ & 1.00 & & & & & \\
Conduct problems (Beh) & $-0.19^{*}$ & $0.34^{* * *}$ & 1.00 & & & & \\
Hyperactivity (Hyp) & 0.09 & $0.30^{* * *}$ & $0.41^{* * *}$ & 1.00 & & & \\
Peer-related problems (Per) & $0.23^{* * *}$ & $0.44^{* * *}$ & $0.29^{* * *}$ & $0.17^{* *}$ & 1.00 & & \\
Prosocial behavior (Soc) & 0.07 & $-0.17^{* *}$ & $-0.42^{* * *}$ & $-0.25^{* * *}$ & $-0.27^{* * *}$ & 1.00 & \\
HRQoL & $-0.27^{* * *}$ & $-0.50^{* * *}$ & $-0.25^{* * *}$ & $-0.23^{* * *}$ & $-0.44^{* * *}$ & $0.19^{* *}$ & 1.00 \\
\hline
\end{tabular}

BMI-SDS, body mass index standard deviation score; Emo, emotional problems; Beh, conduct problems; Hyp, hyperactivity; Per, peer-related problems; Soc, prosocial behavior; HRQoL, health-related quality of life. ${ }^{*} p<$ $0.05, * * p<0.01, * * * p<0.001$.

effects were found for the BMI-SDS and hyperactivity; the younger age-group had a significantly lower BMI-SDS than the older age-group $(t[224.2]=-5.63, p<0.001)$. Additionally, the younger age-group scored significantly higher on hyperactivity than the older age-group ( $t$ [313] $=3.25, p=0.001)$. Hence, both variables were included in the mediation model as covariates to control for these effects.

\section{Partial Correlations}

Table 3 presents the partial correlations between the potential mediation variables while controlling for gender and age-group. The prerequisite of significant correlations between the potential mediating variables "hyperactivity" and "prosocial behavior" and the predictor "BMI-SDS" was not given. Thus, 3 simple mediation models with the 2 covariates "gender" and "age-group" were tested:

1. The relationship between BMI-SDS and global HRQoL with emotional problems as a mediator

2. The relationship between BMI-SDS and global HRQoL with conduct problems as a mediator

3. The relationship between BMI-SDS and global HRQoL with peer-related problems as a mediator.

It was assumed that mental health problems would mediate the inverse association of the BMI-SDS with global HRQoL.

\section{Mediation Analyses}

In all 3 models, BMI-SDS was included as the independent variable $(X)$, and global HRQoL was included as the dependent variable $(Y)$. The mediators $(\mathrm{M})$ differed in the 3 models. Emotional problems were investigated in model
1 , conduct problems in model 2 , and peer-related problems in model 3. The standardized coefficient $(\beta)$ is reported for the 4 pathways $\left(a, b, c, c^{\prime}\right)$ and the indirect effect $(\mathrm{ab})$.

A significant total and direct effect was identified for all 3 mediation models. Furthermore, mediation effects were found in all 3 models. Neither the unstandardized nor the partially or completely standardized effects of the 95\% bootstrap confidence intervals included zero (Fig. 1-3). When mental health problems were included as mediators, all direct effects were reduced in magnitude but still remained significant. Moreover, both mediating pathways were also significant in all 3 models.

\section{Mediation Model 1}

The model illustrates that the explanation of the variance in global HRQoL increased from $7 \%$ to $28 \%$ when emotional problems were included as a mediator in the association between BMI-SDS and global HRQoL ( $c$ : coefficient $=-0.29, \mathrm{SE}=0.05, p<0.001,95 \% \mathrm{CI}[-0.40$; $-0.17] ; c^{\prime}$ : coefficient $=-0.19, \mathrm{SE}=0.05, p<0.01,95 \% \mathrm{CI}$ $[-0.30 ;-0.09]$; Fig. 1$)$. Accordingly, the effect size increased from small to large. Thus, a higher BMI-SDS predicted higher levels of emotional problems, which subsequently predicted lower global HRQoL.

\section{Mediation Model 2}

The model only revealed an increase in the proportion of the explained variance in global HRQoL from $7 \%$ to $12 \%$ when conduct problems were considered a mediator in the relation between BMI-SDS and global HRQoL ( $c$ : coefficient $=-0.29, \mathrm{SE}=0.05, p<0.001,95 \% \mathrm{CI}[-0.40$; $-0.17] ; c^{\prime}$ : coefficient $=-0.26, \mathrm{SE}=0.06, p<0.001,95 \%$ CI $[-0.37 ;-0.15]$; Fig. 2). Both effect sizes were small. 
Fig. 1. Model 1: mediating effects of emotional problems on the relation between BMI-SDS and global HRQoL ( $\beta=$ standardized regression coefficient, ${ }^{*} p<0.05$, $\left.{ }^{* *} p<0.01,{ }^{* * *} p<0.001\right)$. Note: simple mediation analyses using "gender $\left(C_{1}\right)$ " and "age-group $\left(C_{2}\right)$ " as covariates $(a=$ direct path of BMI-SDS; $X$ on mental health problems $(M), b=$ direct path of mental health problems on global HRQoL $(Y), c=$ path of BMI-SDS $(X)$ on HRQoL $(Y)$, and $c^{\prime}=$ path of BMI-SDS $(X)$ on HRQoL $(Y)$ mediated by mental health problems $(\mathrm{M})$. SE = standard error, $95 \% \mathrm{~B}-\mathrm{CI}=95 \%$ bootstrap confidence interval; BMI-SDS, body mass index standard deviation score; HRQoL, health-related quality of life.

Fig. 2. Model 2: mediating effects of conduct problems on the relation between BMI-SDS and global HRQoL ( $\beta=$ standardized regression coefficient, ${ }^{*} p<0.05$, $\left.{ }^{* *} p<0.01,{ }^{* * *} p<0.001\right)$. SE $=$ standard error, $95 \%$ B-CI $=95 \%$ bootstrap confidence interval; BMI-SDS, body mass index standard deviation score; HRQoL, health-related quality of life.

Fig. 3. Model 3: mediating effects of peerrelated problems on the relation between BMI-SDS and global HRQoL ( $\beta=$ standardized regression coefficient, ${ }^{*} p<0.05$, $\left.{ }^{* *} p<0.01,{ }^{* * *} p<0.001\right)$. SE = standard error, $95 \%$ B-CI $=95 \%$ bootstrap confidence interval; BMI-SDS, body mass index standard deviation score; HRQoL, health-related quality of life.
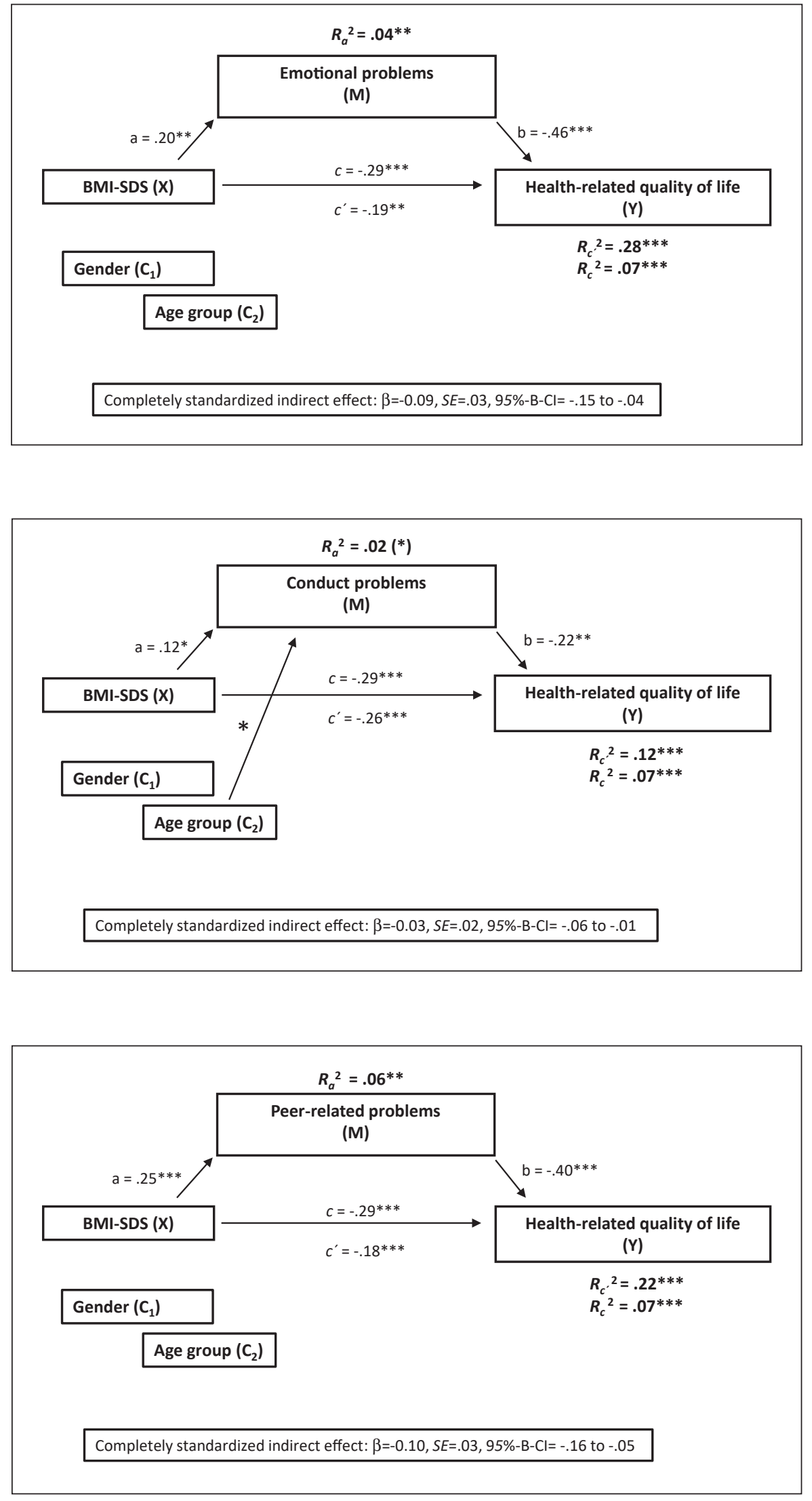


\section{Mediation Model 3}

The explained variance in HRQoL increased from $7 \%$ to $22 \%$ when peer-related problems were included in the mediation model as a mediator $(c$ : coefficient $=-0.29$, $\mathrm{SE}=0.05, p<0.001,95 \%$ CI $[-0.40 ;-0.17] ; c^{\prime}$ : coefficient $=-0.18, \mathrm{SE}=0.05, p<0.001,95 \% \mathrm{CI}[-0.29 ;-0.08]$; Fig. 3). Accordingly, the effect size increased from small to moderate.

\section{Moderating Effects}

No gender effects could be ascertained. In contrast, a significant correlation was indicated for the covariate "age-group" in mediation model 2 . The parents reported more conduct problems among adolescents aged 12-14 years than among adolescents aged $15-17$ years $\left(f_{2}\right.$ : coefficient $=-0.24, \mathrm{SE}=0.12, p<0.05,95 \% \mathrm{CI}[-0.48 ;-0.01]$; Fig. 2).

\section{Discussion}

The present study provided results regarding the relations among BMI-SDS, parent proxy-reported mental health problems, and self-reported global HRQoL in adolescent inpatients with obesity, and these findings are of important clinical relevance. First, BMI-SDS significantly predicted global HRQoL. Second, emotional, conduct, and peer-related problems mediated the associations between BMI-SDS and global HRQoL. Moderating effects of gender and age-group were exclusively found for conduct problems, indicating that conduct problems are increased among early adolescents compared with late adolescents. Research on age effects in population-based studies revealed rather inconclusive results, showing increased conduct problems in early adolescents compared with late children [45] and enhanced conduct problems among children and early adolescents than among late adolescents [46].

In bivariate partial correlation analyses, BMI-SDS was negatively associated with emotional, conduct, and peerrelated problems, which is consistent with prior results showing an adverse impact of obesity and BMI on mental health problems [18-20]. In contrast, BMI-SDS was not significantly linked with hyperactivity or prosocial behavior. Past research has provided inconclusive results regarding the relation of attention-deficit hyperactivity disorder (ADHD) with obesity, studies have both shown that childhood ADHD does not predict adult BMI when the analyses are controlled for conduct disturbance symptoms [47] and suggested that ADHD has predictive value for obesity [48]. However, the use of a screening instrument versus a clinical interview seems to weaken the association [48]. Consistent with earlier cross-sectional studies with population-based samples, mental health problems were inversely associated with global HRQoL $[15,27]$.

The present results extend the research on the mediating role of mental health problems in the association between BMI-SDS and global HRQoL. As expected, BMISDS was positively linked with emotional, conduct, and peer-related problems, and these mental health problems were subsequently inversely associated with global HRQoL. Interestingly, the mediating value of emotional problems was clinically significant, showing an increase from a small to a large effect size. The mediating effect of peer-related problems had a somewhat decreased association, with moderate clinical significance. In contrast, conduct problems had low clinical significance. As cited above, when the direct effects of BMI on mental health problems were investigated in a population-based study, the same association was found for self-reported peerrelated problems [19]. Moreover, these authors also reported weaker associations for conduct and emotional problems, which exhibited a 1.90- and 1.55-fold increased risk among adolescents with obesity, respectively. Furthermore, gender effects on emotional problems were found in this substudy of the KiGGS; multivariate analyses yielded significant effects on emotional problems for females, but not males, with obesity. In contrast, moderating effects of gender were not be found in the present mediation model. Variable methods and factors, such as the type, size, and age range of the sample, as well as the type of informant (parental- or self-report), may account for the different effects.

However, past research has underscored the crucial impact of internalizing problems on obesity (e.g., [22]) and on HRQoL (e.g., [15]). Other studies have added to the growing evidence of the crucial role of mental health problems in the onset and maintenance of obesity (e.g., [17]). Hence, the mediation results of this study have important implications for research and practice, suggesting that mental health problems may play a key role in the relation of BMI-SDS and HRQoL. Existing multimodal intervention programs for adolescents with obesity, which focused on a combination of diet, physical activity, and behavioral components and displayed short-term intervention effects [49], can be modified accordingly with the aim of extending the effects of such interventions in the long-term. First, the finding of adverse influences of emotional, conduct, and peer-related 
problems underlines the importance of emotion regulation training to improve adolescents' maladaptive adjustment to their increased perceived stress. Based on a framework of a stress-obesity relationship in which emotion regulation is assumed to be the missing link, an inpatient program has been developed [50]. An ongoing evaluation study will provide important results for the future. Second, the moderate mediation effect of peerrelated problems may reflect the increased perceived interpersonal stress among adolescents with obesity, especially the experience of weight-related teasing and victimization, which has been shown to be a significant mediator in the relation between BMI or obesity and psychosocial health $[18,26,28,29]$. Similarly, the importance of addressing weight stigma "as a psychosocial contributor to obesity" in improving the success of weight management programs was emphasized in a current study [51]. Thus, the implementation of elements aimed at improving social-emotional competencies is recommended.

Some limitations of this study should be noted. First, when a clinical sample is used in a study, uncontrolled selection effects cannot be excluded. However, the main intention of the present study was to identify significant psychological mediating factors, that can be addressed in future intervention programs. Nonetheless, the increased odds of mental health problems among adolescent patients with obesity should be compared with those of age- and gender-matched healthy controls in the future. Second, based on the findings of bidirectional associations between BMI or obesity and psychosocial health, the cross-sectional design of the study must be discussed. Although conclusions about the direction of associations cannot be drawn, increasing consensus in the literature suggests that BMI or obesity predicts psychosocial health among children and adolescents rather than the reverse [25]. Nevertheless, future studies should examine these relations using a prospective study design. A third limitation refers to the use of single informants; mental health problems were not measured by self-reports in the first research project due to concerns about the restricted reliability of the SDQ-S [18]. Although the SDQ-S was integrated into the second research project, which had a sample of $N=142$, the internal consistencies were insufficient, and these self-reports could not be used in further analyses. However, some research has indicated good agreement between self- and parent proxy-reported emotional problems and total scores based on independent Student's $t$ tests [52]. HRQoL was only assessed by a self-report measure. However, studies indicate that parents overestimate the impact of obesity on the HRQoL of their children $[12,53]$.

\section{Conclusions}

The present study extends previous evidence of the significant association between obesity and psychosocial factors among adolescents. Mental health problems may be one salient pathway through which BMI-SDS impairs global HRQoL in adolescents with obesity. Hence, early diagnosis of mental health problems is recommended, and early interventions should be applied to identified risk groups. In agreement with current treatment guidelines, the present findings support the notion that in the conceptualization of multimodal interventions, increased attention to psychosocial factors is warranted. Thus, the promotion of emotion regulation and social-emotional competencies is advised. However, due to the crucial impact of social factors, such as weight-related stigmatization in society, selfmanagement programs should be supplemented by setting-based interventions to better prevent the onset and maintenance of obesity and comorbid mental health problems in adolescents.

\section{Statement of Ethics}

The analyzed data combined data sets from 2 research projects that received full approval from the Ethical Review Board of the "Ärztekammer SH" (approval no. 083/12) and the German Psychological Society (DGPs; approval no. PH_112015) and was conducted in accordance with the 1964 Helsinki Declaration and its later amendments. Written informed consent was obtained from the parents and adolescents included in the study.

\section{Conflict of Interest Statement}

The authors have no conflicts of interest to declare.

\section{Funding Sources}

This study was funded by the German Pension Insurance North. Julian Wienert gratefully acknowledges the support of the Leibniz ScienceCampus Digital Public Health Bremen (http:// www.lsc-diph.de), which is jointly funded by the Leibniz Association (W4/2018), the Federal State of Bremen and the Leibniz Institute for Prevention Research and Epidemiology - BIPS. 


\section{Author Contributions}

R. Stachow collected the data, and P. Hampel analyzed the data and wrote the paper. J. Wienert provided essential support during the writing process and collaborated on 1 of the 2 studies. All authors agreed to publish the paper.

\section{Data Availability Statement}

The data sets generated during and/or analyzed during the current study are available from the corresponding author on reasonable request.

\section{References}

1 Skinner AC, Ravanbakht SN, Skelton JA, Perrin EM, Armstrong SC. Prevalence of obesity and severe obesity in US children, 1999-2016. Pediatrics. 2018 Mar;141(3):e20173459.

2 Ng M, Fleming T, Robinson M, Thomson B, Graetz N, Margono C, et al. Global, regional, and national prevalence of overweight and obesity in children and adults during 19802013: a systematic analysis for the Global Burden of Disease Study 2013. Lancet. 2014 Aug; 384(9945):766-81.

3 Kurth BM, Schaffrath Rosario A. The prevalence of overweight and obese children and adolescents living in Germany. Results of the German health interview and examination survey for children and adolescents (KiGGS). Bundesgesundheitsblatt Gesundheitsforschung Gesundheitsschutz. 2007 May;50(5-6): 736-43.

4 Brettschneider A-K, Schaffrath Rosario A, Kuhnert R, Schmidt S, Wiegand S, Ellert U, et al. Updated prevalence rates of overweight and obesity in 11- to 17-year-old adolescents in Germany. Results from the telephone-based KiGGS Wave 1 after correction for bias in selfreports. BMC Public Health. 2015;15:1101.

5 Brettschneider AK, Schienkiewitz A, Schmidt S, Ellert U, Kurth BM. Updated prevalence rates of overweight and obesity in 4- to 10 -year-old children in Germany. Results from the telephone-based KiGGS Wave 1 after correction for bias in parental reports. Eur J Pediatr. 2017 Apr;176(4):547-51.

6 Schienkiewitz A, Brettschneider AK, Damerow S, Schaffrath Rosario A. Overweight and obesity among children and adolescents in Germany. Results of the cross-sectional KiGGS Wave 2 study and trends. J Health Monitor. 2018 Mar;3(1):16-22.

7 Russell-Mayhew S, McVey G, Bardick A, Ireland A. Mental health, wellness, and childhood overweight/obesity. J Obes. 2012;2012: 281801.

8 Sarwer DB, Heinberg LJ. A review of the psychosocial aspects of clinically severe obesity and bariatric surgery. Am Psychol. 2020 FebMar;75(2):252-64.

9 Buttitta M, Iliescu C, Rousseau A, Guerrien A. Quality of life in overweight and obese children and adolescents: a literature review. Qual Life Res. 2014 May;23(4):1117-39.

10 Taner Y, Törel-Ergür A, Bahçivan G, Gürdag M. Psychopathology and its effect on treatment compliance in pediatric obesity patients. Turk J Pediatr. 2009 SepOct;51(5): 466-71.
11 Tsiros MD, Olds T, Buckley JD, Grimshaw P, Brennan L, Walkley J, et al. Health-related quality of life in obese children and adolescents. Int J Obes. 2009 Apr;33(4):387-400.

12 Ul-Haq Z, Mackay DF, Fenwick E, Pell JP. Meta-analysis of the association between body mass index and health-related quality of life among adults, assessed by the SF-36. Obesity. 2013 Mar;21(3):E322-7.

13 Keating CL, Moodie ML, Swinburn BA. The health-related quality of life of overweight and obese adolescents: a study measuring body mass index and adolescent-reported perceptions. Int J Pediatr Obes. 2011 Oct;6(56):434-41.

14 Wille N, Bullinger M, Holl R, Hoffmeister U, Mann R, Goldapp C, et al. Health-related quality of life in overweight and obese youths: results of a multicenter study. Health Qual Life Outcomes. 2010;8:36.

15 Baumgarten F, Cohrdes C, Schienkiewitz A, Thamm R, Meyrose AK, Ravens-Sieberer U. Health-related quality of life and its relation to chronic diseases and mental health problems among children and adolescents. Results from KiGGS wave 2. Bundesgesundheitsblatt Gesundheitsforschung Gesundheitsschutz. 2019 Oct;62(10):1205-14.

16 Varni JW, Limbers CA, Burwinkle TM. Impaired health-related quality of life in children and adolescents with chronic conditions: a comparative analysis of 10 disease clusters and 33 disease categories/severities utilizing the PedsQL 4.0 Generic Core Scales. Health Qual Life Outcomes. 2007 Jul;5:43.

17 Sagar R, Gupta T. Psychological aspects of obesity in children and adolescents. Indian J Pediatr. 2018 Jul;85(7):554-9.

18 van Vuuren CL, Wachter GG, Veenstra R, Rijnhart JJM, van der Wal MF, Chinapaw MJM, et al. Associations between overweight and mental health problems among adolescents, and the mediating role of victimization. BMC Public Health. 2019;19(1):612.

19 Krause L, Kleiber D, Lampert T. Psychische Gesundheit von übergewichtigen und adipösen Jugendlichen unter Berücksichtigung von Sozialstatus und Schulbildung. Präv Gesundheitsf. 2014 Nov;9(4):264-73.

20 Gibson-Smith D, Halldorsson TI, Bot M, Brouwer IA, Visser M, Thorsdottir I, et al. Childhood overweight and obesity and the risk of depression across the lifespan. BMC Pediatr. 2020;20(1):25.
21 Mohammadi MR, Khaleghi A, Mostafavi SA, Ahmadi N, Kamali K, Hooshyari Z, et al. Gender determines the pattern of correlation between body mass index and major depressive disorder among children and adolescents: results from Iranian children and adolescents' psychiatric disorders study. Child Obes. 2019; 15(5):331-7.

22 Eschenbeck H, Kohlmann CW, Dudey S, Schurholz T. Physician-diagnosed obesity in German 6- to 14-year-olds. Prevalence and comorbidity of internalising disorders, externalising disorders, and sleep disorders. Obes Facts. 2009;2(2):67-73.

23 Geoffroy MC, Li L, Power C. Depressive symptoms and body mass index: co-morbidity and direction of association in a British birth cohort followed over 50 years. Psychol Med. 2014 Sep;44(12):2641-52.

24 Anderson SE, Cohen P, Naumova EN, Jacques PF, Must A. Adolescent obesity and risk for subsequent major depressive disorder and anxiety disorder: prospective evidence. Psychosom Med. 2007 Nov;69(8):740-7.

25 Mühlig Y, Antel J, Föcker M, Hebebrand J. Are bidirectional associations of obesity and depression already apparent in childhood and adolescence as based on high-quality studies? A systematic review. Obes Rev. 2016 Mar; 17(3):235-49.

26 Mond J, van den Berg P, Boutelle K, Hannan $P$, Neumark-Sztainer D. Obesity, body dissatisfaction, and emotional well-being in early and late adolescence: findings from the project EAT study. J Adolesc Health. 2011;48(4): 373-8.

27 Otto C, Haller AC, Klasen F, Hölling H, Bullinger M, Ravens-Sieberer U. Risk and protective factors of health-related quality of life in children and adolescents: results of the longitudinal BELLA study. PLoS One. 2017;12(12): e0190363.

28 Guardabassi V, Mirisola A, Tomasetto C. How is weight stigma related to children's health-related quality of life? A model comparison approach. Qual Life Res. 2018 Jan; 27(1):173-83.

29 Blanco M, Solano S, Alcántara AI, Parks M, Román FJ, Sepúlveda AR. Psychological wellbeing and weight-related teasing in childhood obesity: a case-control study. Eat Weight Disord. 2020 Jun;25(3):751-9.

30 Hampel P, Petermann F. Perceived stress, coping, and adjustment in adolescents. J Adolesc Health. 2006 Apr;38(4):409-15. 
31 Guideline Development Panel for Treatment of Obesity, American Psychological Association. Summary of the clinical practice guideline for multicomponent behavioral treatment of obesity and overweight in children and adolescents. Am Psychol. 2020 Feb-Mar; 75(2):178-88

32 Kromeyer-Hauschild K, Wabitsch M, Kunze D, Geller F, Geiß HC, Hesse V, et al. Perzentile für den body-mass-Index für das Kindes- und Jugendalter unter Heranziehung verschiedener deutscher Stichproben. Monatsschr Kinderheilkd. 2001 Aug;149(8):807-18.

33 Woerner W, Becker A, Friedrich C, Klasen H, Goodman R, Rothenberger A. Normative data and evaluation of the German parentrated strengths and difficulties questionnaire (SDQ): results of a representative field study. Z Kinder Jugendpsychiatr Psychother. 2002 May;30(2):105-12.

34 Goodman A, Goodman R. Strengths and difficulties questionnaire as a dimensional measure of child mental health. J Am Acad Child Adolesc Psychiatry. 2009 May;48(4):400-3.

35 Mieloo C, Raat H, van Oort F, Bevaart F, Vogel I, Donker M, et al. Validity and reliability of the strengths and difficulties questionnaire in 5-6 year olds: differences by gender or by parental education? PLoS One. 2012;7(5): e36805.

36 Woerner W, Becker A, Rothenberger A. Normative data and scale properties of the German parent SDQ. Eur Child Adolesc Psychiatry. 2004;13 Suppl 2:II3-10.

37 The DISABKIDS Group Europe. The DISABKIDS questionnaires: Quality of life questionnaires for children with chronic conditions. Lengerich: Pabst Science Publishers; 2006.
38 Chaplin JE, Hallman M, Nilsson NO, Lindblad B. The reliability of the disabled children's quality-of-life questionnaire in Swedish children with diabetes. Acta Paediatr. 2012 May;101(5):501-6.

39 Simeoni MC, Schmidt S, Muehlan H, Debensason D, Bullinger M; DISABKIDS Group. Field testing of a European quality of life instrument for children and adolescents with chronic conditions: the 37-item DISABKIDS chronic generic module. Qual Life Res. 2007 Jun;16(5):881-93.

40 Hayes AF. Introduction to mediation, moderation, and conditional process analysis: a regression-based approach. 2nd ed. New York: The Guilford Press; 2018.

41 Field A. Discovering statistics using IBM SPSS statistics. 4th ed. Los Angeles: Sage; 2013.

42 Eid M, Gollwitzer M, Schmitt M. Statistik und Forschungsmethoden [Statistics and research methods]. Weinheim: Beltz; 2010.

43 Belsley DA, Kuh E, Welsch RE. Regression diagnostics: identifying influential data and sources of collinearity. New York, NY: WileyInterscience; 2005.

44 Cohen J. Statistical power analysis for the behavioural sciences. 2nd ed. Hillsdale: Lawrence Earlbaum Associates; 1988.

45 Deighton J, Lereya ST, Casey P, Patalay P, Humphrey N, Wolpert M. Prevalence of mental health problems in schools: poverty and other risk factors among 28000 adolescents in England. Br J Psychiatry. 2019 Jan;3: $1-3$.

46 Hölling H, Erhart M, Ravens-Sieberer U, Schlack R. Behavoural problems in children and adolescents. First results from the German health interview and examination survey for children and adolescents (KiGGS) Bundesgesundheitsblatt Gesundheitsforschung Gesundheitsschutz. 2007 May;50(56):784-93.
47 Korczak DJ, Lipman E, Morrison K, Duku E, Szatmari P. Child and adolescent psychopathology predicts increased adult body mass index: results from a prospective community sample. J Dev Behav Pediatr. 2014 Feb-Mar; 35(2):108-17.

48 Cortese S, Moreira-Maia CR, St Fleur D, Morcillo-Peñalver C, Rohde LA, Faraone SV. Association between $\mathrm{ADHD}$ and obesity: a systematic review and meta-analysis. Am J Psychiatry. 2016 Jan;173(1):34-43.

49 Al-Khudairy L, Loveman E, Colquitt JL, Mead E, Johnson RE, Fraser H, et al. Diet, physical activity and behavioural interventions for the treatment of overweight or obese adolescents aged 12 to 17 years. Cochrane Database Syst Rev. 2017 Jun;6:CD012691.

50 Debeuf T, Verbeken S, Boelens E, Volkaert B, van Malderen E, Michels N, et al. Emotion regulation training in the treatment of obesity in young adolescents: protocol for a randomized controlled trial. Trials. $2020 \mathrm{Feb} / \mathrm{Mar}$; 21(1):153.

51 Puhl RM, Himmelstein MS, Pearl RL. Weight stigma as a psychosocial contributor to obesity. Am Psychol. 2020 Feb-Mar;75(2):27489.

52 Arman S, Amel AK, Maracy MR. Comparison of parent adolescent scores on strengths and difficulties questionnaire. J Res Med Sci. 2013 Jun;18(6):501-5.

53 Helseth S, Haraldstad K, Christophersen KA. A cross-sectional study of health related quality of life and body mass index in a Norwegian school sample (8-18 years): a comparison of child and parent perspectives. Health Qual Life Outcomes. 2015;13:47. 